\title{
Neurolinguistic Differences in Language Processing Between the Sexes
}

\author{
Georgia Andreou* and Anargyros Karapetsas
}

Department of Special Education, University of Thessaly, Greece

\begin{abstract}
The method of visual Event Related Potentials (ERPs) was used to investigate the participation of the left and right occipital and temporal lobes of males and females in performing rhyme and semantic tasks. 60 Greek students, 30 males and 30 females, participated, who were all right handed and native speakers of the Greek language. In both tasks, females seemed to implicate both cerebral hemispheres thus showing a weaker pattern of lateralization than males. In addition, females were proved better than males in performing both tasks, since they showed a statistically significant superiority, when compared to males, in the mean latencies of all the components of left and right occipital and temporal lobes. Our findings imply that although the left cerebral hemisphere (LH) is believed to be dominant for language, the right cerebral hemisphere (RH) is also involved in certain components of language processing.
\end{abstract}

Keywords: Sex, language, ERPs.

\section{INTRODUCTION}

Investigations on cerebral lateralization for language $[1,2,3]$ support the idea that although for most people, all right-handers and most left-handers, the left cerebral hemisphere (LH) is dominant for language, the right cerebral hemisphere (RH) is also involved in certain components of language processing. Evidence for differential lateralization of language which derives both from clinical population $[4,5]$ and from brain intact individuals [6,7], suggests that the LH is predominantly specialised for syntactic and phonetic component processes of language, while orthographic and semantic components are more bilaterally mediated $[3,8,9]$.

Sex has proved to have an effect on cerebral lateralization for language. Females show a weak pattern of lateralization for language while males show a more even one probably because quick maturational rates on the part of the females influences the way they involve their LH and RH in the processing of language. Previous findings showed that females implicate both $\mathrm{LH}$ and $\mathrm{RH}$ in language processing while males show a preference for the $\mathrm{LH}$ while performing language tasks [10-13].

Event-related potentials (ERPs) in response to visually presented linguistic stimuli have often been used to investigate functional cerebral lateralization for language $[1,14,15]$. Differences in the latency of the visual component N1 (N75) have been associated with aspects of attention, of P1 (P100) with the interpretation of visual stimuli, of N2 (N145) with difficulties in response selection and of P2 (P165) with word reading and perceptual quality of words [16-18].

In view of the above findings, in the present study we intend to investigate the participation of the left and right Occipital and Temporal lobes in the processing of language in males and females. More specifically, the aims of our study are a) to detect possible differential participation of the

*Address correspondence to this author at the Department of Special Education, University of Thessaly, Home address: 37-41 Herodotou str., 41222 Larissa, Greece; Tel: 00302410627854 ; E-mail: andreou@uth.gr two cerebral hemispheres in males and females in language tasks and b) to investigate the role of the left ( $\mathrm{LH})$ and right (RH) cerebral hemispheres in specific components of language, namely rhyme and semantic tasks.

\section{METHODS}

A total of 60 Greek students (30 males and 30 females) from the University of Thessaly participated (mean age: 21.5, SD: 1.3 years). All subjects were native speakers of Greek and strongly right-handed as assessed by the Edinburgh Handedness Inventory [19]. They all had normal or corrected-to-normal vision. A total of 16 three- to six-letter pairs of words were flashed for $200 \mathrm{msec}$ horizontally at $2^{\circ}$ to the right or left of the center of a screen which was marked by a red dot. The stimuli subtended $2.0-3.4^{\circ}$ of visual angle horizontally and $0.4^{\circ}$ vertically. While fixating the red dot, the participants were asked to silently read and think whether the pair of words presented on the screen rhymed [e.g. fatmat, face-race (equivalent pairs in Greek)] or had a semantic relationship [e.g. desk-chair, ear-nose (the equivalents in Greek)]. For the first eight trials, electrodes were attached to left occipital (O1) and left temporal (T1) loci and for the following eight trials electrodes were attached to right occipital (O2) and right temporal (T2) loci.

The existence of a number of factors in our experiment demanded the use of a mixed-design analysis of variance (MANOVA) in order to detect possible statistically significant $(\mathrm{p}<.05)$ interactions among them. Left and right occipital and temporal (left vs right occipital and left vs right temporal), type of task (rhyme vs semantic) and sex (males vs females) were used as factors and the latencies of the components N1, P1, N2 and P2 were the dependent variables. In order to make our results stronger the statistically significant interactions $(\mathrm{p}<.05)$ found from the above analysis were further evaluated by post hoc Scheffe F-test. The SPSS statistical programme was used to analyse the data.

\section{RESULTS}

A within-subjects 2 (left-right: left vs right occipital and left vs right temporal) X 2 (type of task: rhyme vs semantic) 
X 2 (sex: males vs females) mixed-design ANOVA revealed statistically significant $(\mathrm{p}<.05)$ main effects for all three factors: left-right $[\mathrm{F}(2.000)=7.922, \mathrm{p}=.000]$, type of task $[\mathrm{F}(2.000)=1343.635, \mathrm{p}=.000]$ and $\operatorname{sex}[\mathrm{F}(2.000)=3.154, \mathrm{p}=$ $.000]$. Two- and three-way statistically significant interactions were also obtained: left-right $\mathrm{X}$ type of task $[\mathrm{F}(2.000)=$ $6.865, \mathrm{p}=.000]$, left-right $\mathrm{X} \operatorname{sex}[\mathrm{F}(2.000)=3.255, \mathrm{p}=.000]$, type of task $\mathrm{X}$ sex $[\mathrm{F}(2.000)=22.824, \mathrm{p}=.000]$ and left-right $X$ type of task $X$ sex $[F(2.000)=7.964, p=.000]$. Furthermore, a within subjects mixed-design ANOVA (left-right $\mathrm{X}$ type of task X sex) was performed on latencies of the occipital N1, P1, N2 and temporal N2, P2 components. Mean latencies of all the components of the left and right occipital and temporal lobes for the rhyme and semantic tasks performed by males and females are presented in Table 1. Statistically significant main effects for the occipital N1 were obtained for left-right $[\mathrm{F}(1)=195.3, \mathrm{p}=.001]$, sex $[\mathrm{F}(1)=$ $1.193, \mathrm{p}=.001]$, left-right $\mathrm{X} \operatorname{sex}[\mathrm{F}(1)=1.267, \mathrm{p}=001]$ and left-right $X$ type of task $X$ sex $[F(1)=123.048, p=.005]$. For the occipital P1 we found statistically significant main effects for left-right $[\mathrm{F}(1)=174.264, \mathrm{p}=.001]$, type of task $[F(1)=1106.765, p=.01$, sex $[F(1)=2.045, p=.001]$, leftright $\mathrm{X}$ type of task $[\mathrm{F}(1)=57.056, \mathrm{p}=.001]$, left-right $\mathrm{X}$ sex $[F(1)=47.543, p=.001]$ and left-right $X$ type of task $X$ sex $[F(1)=223.478, p=.002]$. A statistically significant main effect for the occipital $\mathrm{N} 2$ was obtained only for sex $[\mathrm{F}(1)=$ $1.078, \mathrm{p}=.001]$. Statistically significant main effects were obtained for the temporal $\mathrm{N} 2$ latency for left-right $[\mathrm{F}(1)=$ 4.592, $\mathrm{p}=.001]$, type of task $[\mathrm{F}(1)=794.567, \mathrm{p}=.001]$, sex $[F(1)=1.194, p=.001]$, left-right $X$ type of task $[F(1)=6.744$, $\mathrm{p}=.002]$, left-right $\mathrm{X} \operatorname{sex}[\mathrm{F}(1)=578.619, \mathrm{p}=.001]$ and leftright $\mathrm{X}$ type of task $\mathrm{X}$ sex $[\mathrm{F}(1)=5.640, \mathrm{p}=.005]$. We also found statistically significant main effects for the temporal P2 latency for left-right $[\mathrm{F}(1)=198.481, \mathrm{p}=001]$, type of task $[F(1)=1726.629, p=.001]$, sex $[F(1)=1.567, p=.001]$, left-right $\mathrm{X}$ type of task $[\mathrm{F}(1)=72.754, \mathrm{p}=.001]$, left-right $\mathrm{X}$ sex $[F(1)=697.563, p=.001]$, type of task $X$ sex $[F(1)=$ $344.789, p=.001]$ and left-right $X$ type of task $X$ sex $[\mathrm{F}(1)=345.272, \mathrm{p}=.01]$.

Post hoc Scheffe F-test performed on the latencies of the above two- and three-way statistically significant $(\mathrm{p}<.05)$ interactions revealed that in the rhyme task there was a left occipital and temporal superiority on the part of males for occipital $\mathrm{N} 1[73.57, \mathrm{SD}=0.78$ vs $75.93, \mathrm{SD}=0.45]$ and $\mathrm{P} 1$ latency [104.56, $\mathrm{SD}=0.74$ vs $107.04, \mathrm{SD}=0.96]$ and for temporal N2 [182.42, SD 0.67 vs 185.45 , SD 0.56] and P2 latency [194.67, SD 0.45 vs 197.34, SD 0.34] while in females such a superiority was observed only for P1 latency [101.53, $\mathrm{SD}=.045$ vs $104.67, \mathrm{SD}=0.88]$. In the semantic task there was only a left temporal superiority and only on the part of males for $\mathrm{N} 2$ [173.89, $\mathrm{SD}=0.84$ vs $176.60, \mathrm{SD}=0.34]$ and $\mathrm{P} 2$ latency [194.29, $\mathrm{SD}=0.77$ vs $196.48, \mathrm{SD}=0.89]$.

\section{DISCUSSION}

Based on the results described above, our study suggests a LH superiority for rhyme tasks on the part of males since a left occipital and temporal superiority was found in almost all the components of the waveforms obtained for this task. Our finding lends support to previous studies which suggested a LH superiority in the processing of rhyme tasks $[3,9]$ and a left temporal lobe superiority during silent reading of words [20]. In the semantic task, there was only a left temporal superiority and only on the part of males confirming previous findings that semantic components of language are more bilaterally mediated [8].

In both tasks, females showed a weaker pattern of lateralization for language than males, indicating a bilateral participation not only for semantic tasks but also for rhyme tasks, a result which does not support previous findings claiming that rhyme decision is one of the processes over which the LH appears to have almost sole control $[9,21]$. In addition, females were proved better than males in performing both tasks since there was a female superiority in the mean latencies of all the components of left and right occipital and temporal lobes for both rhyme and semantic tasks. This finding lends support to previous studies which found a female superiority on language tasks $[10,11]$ and as it has been claimed can be explained by anatomical differences in the cerebral hemispheres of the two sexes and different maturational rates on the part of the two sexes $[12,13]$.

\section{CONCLUSION}

Our findings are a step forward towards the belief that both cerebral hemispheres participate in language processing, an action which was previously thought to be under the sole control of the LH. In addition, they help to delineate the differences between the sexes in language processing suggesting the differential lateralization of language depending on sex.

However, further research is needed into the field of language processing between the sexes, using a wider range of language stimuli in order to elucidate the role of sex in the

Table 1. Mean Latencies* of all the Components of Left and Right Occipital and Temporal Lobes for all Tasks in Males and Females

\begin{tabular}{|c|c|c|c|c|c|c|c|c|c|c|c|c|c|c|c|c|c|c|c|c|}
\hline \multirow{3}{*}{ Latency } & \multicolumn{6}{|c|}{ Left Occipital } & \multicolumn{4}{|c|}{$\underline{\text { Left Temporal }}$} & \multicolumn{6}{|c|}{ Right Occipital } & \multicolumn{4}{|c|}{ Right Temporal } \\
\hline & \multicolumn{2}{|c|}{ N1 } & \multicolumn{2}{|c|}{ P1 } & \multicolumn{2}{|c|}{ N2 } & \multicolumn{2}{|c|}{ N2 } & \multicolumn{2}{|c|}{$\mathbf{P 2}$} & \multicolumn{2}{|c|}{ N1 } & \multicolumn{2}{|c|}{ P1 } & \multicolumn{2}{|c|}{ N2 } & \multicolumn{2}{|c|}{ N2 } & \multicolumn{2}{|c|}{$\mathbf{P 2}$} \\
\hline & $\mathbf{M}$ & SD & $\mathbf{M}$ & SD & $\mathbf{M}$ & SD & $\mathbf{M}$ & SD & $\mathbf{M}$ & SD & $\mathbf{M}$ & SD & $\mathbf{M}$ & SD & $\mathbf{M}$ & SD & $\mathbf{M}$ & SD & $\mathbf{M}$ & SD \\
\hline \multicolumn{21}{|l|}{ Males } \\
\hline Rhyme task & 73.57 & 0.78 & 104.56 & 0.74 & 165.81 & 0.34 & 182.42 & 0.67 & 194.67 & 0.45 & 75.93 & 0.45 & 107.04 & 0.96 & 166.56 & 0.91 & 185.45 & 0.56 & 197.34 & 0.34 \\
\hline Semantic task & 81.27 & 0.90 & 108.26 & 0.73 & 167.56 & 0.98 & 173.89 & 0.84 & 194.29 & 0.77 & 81.50 & 1.25 & 108.68 & 0.74 & 167.36 & 0.44 & 176.60 & 0.34 & 196.48 & 0.89 \\
\hline \multicolumn{21}{|l|}{ Females } \\
\hline Rhyme task & 70.44 & 0.34 & 101.53 & 0.45 & 162.24 & 0.45 & 180.81 & 0.21 & 191.98 & 0.56 & 71.21 & 0.34 & 104.67 & 0.88 & 162.89 & 0.31 & 181.98 & 0.49 & 192.12 & 0.45 \\
\hline Semantic task & 78.24 & 0.67 & 104.78 & 0.56 & 164.98 & 0.34 & 171.21 & 0.12 & 191.56 & 0.45 & 78.93 & 0.89 & 105.99 & 0.67 & 164.99 & 0.56 & 172.12 & 0.15 & 191.99 & 0.67 \\
\hline
\end{tabular}

*time in msec. 
degree of participation of the two cerebral hemispheres in language processing.

\section{REFERENCES}

[1] Andreou G, Karapetsas A. Hemispheric asymmetries of visual ERPs in left-handed bilinguals. Cogn Brain Res 2001; 12: 333-5.

[2] Beeman M, Friedman RB, Grafman J, Perez E, Dimond S, Lindsay MB. Summation priming and coarse semantic coding in the right hemisphere. J Cogn Neurosci 1994; 6: 26-45.

[3] Karapetsas A, Andreou G. Visual field asymmetries for rhyme and semantic tasks in fluent and non-fluent bilinguals. Brain Lang 2001; 78: 53-61.

[4] Baynes K, Funnel MG, Fowler CA. Hemispheric contributions to the integration of visual and auditory information in speech perception. Percept Psycholinguist 1994; 55: 633-41.

[5] Reuter-Lorenz PA, Baynes K. Modes of lexical access in the callosotomized brain. J Cogn Neurosci 1992; 4: 155-64.

[6] Marsolek CJ, Kosslyn SM, Squire LR. Form-specific visual priming in the right cerebral hemisphere. J Exp Psychol Learn Mem Cogn 1992; 18: 492-508.

[7] Rodel M, Cook ND, Regard M, Landis T. Hemispheric dissociation in judging semantic relations: Complementarity for close and distant associates. Brain Lang 1992; 43: 448-59.

[8] Chiarello C. Interpretation of word meanings by the cerebral hemispheres: One is not enough. In: Schwanenflugel P, Ed. The Psychology of Word Meanings, Lawrence Erlbaum Associates 1991; pp. 146-72.

[9] Rayman J, Zaidel E. Rhyming and the right hemisphere. Brain Lang 1991; 43: 89-105.

[10] Berninger JH, Fuller F. Gender differences in orthographic, verbal and compositional fluency: Implications for diagnosis of writing disabilities in primary grade children. J School Psychol 1992; 45: 427-42.

[11] Haplern DF. Sex differences in cognitive abilities. Hillsdale, NJ: Lawrence Erlbaum Associates 1992.

[12] Inglis J, Ruckman M, Lawson JS, Maclean AW, Monga TN. Sex differences in the cognitive effects of unilateral brain damage. Cortex 1982; 18: 257-76.

[13] McGlone J. Sex differences in human brain asymmetry: A critical survey. Behav Brain Sci 1980; 3: 215-62.

[14] Doyle CM, Rugg DM. Word repetition within-and across-visual fields: An event-related potential study. Neuropsychologia 1988; 36: 1403-15.

[15] Hillyard AS, Anllo-Vento L. Event-related brain potentials in the study of visual selective attention. Proc Natl Acad Sci USA 1998; 95: 781-87.

[16] Helenius P, Salmelin R, Service E, Connolly FJ. Distinct time courses of word and context comprehension in the left Temporal cortex. Brain 1998; 121: 1133-42.

[17] Neville HJ, Kutas M, Chesney G, Schmidt AL. Event-related brain potentials during initial encoding and recognition memory of congruous and incongruous words. J Mem Lang 1986; 25: 75-92.

[18] Neville HJ, Kutas M, Schmidt AL. Event-related potential studies of cerebral specialization during reading: Studies of normal adults. Brain Lang 1982; 16: 300-15.

[19] Oldfield RC. The assessment and analysis of handedness. The Edindurgh Inventory. Neuropsychologia 1971; 9: 97-114.

[20] Price CJ, Wise RJ. Frackowiak RS. Demonstrating the implicit processing of visually presented words and peudowords. Cerebral Cortex 1996; 6: 62-70.

[21] Joanette Y, Goulet P. Word naming in right brain-damaged subjects. In: Chiarello C, Ed. Right Hemisphere Contributions to Lexical Semantics, Springer Verlag 1988; pp. 1-18. 